\title{
DFT Studies of Band Gaps of the Fused Thiophene Oligomers
}

\author{
Choon Sup Ra, ${ }^{\dagger}$ Sanggu Yim, and Gyoosoon Park ${ }^{\circ}$
Department of Chemistr, Kookmin Cniversity, Seoul 136-702. Korea. "E-mail: gparkäkookminachr
${ }^{\dagger}$ Department of Chemistry, Yeumgnam Lniversity, Gvongsan 712-749. Korea
Received October 18.2007

Key Words : Thienoacenes. Thienohelicenes, HOMO-LUMO, DFT

Sulfur-rich anulated oligomers and polymers have attracted growing interest owing to their desirable characteristics (electronic optical. magnetic properties) for fabricating electronic and optical devices. Particularly oligothiophenes composed of multiple thiophene rings joined by single bonds are among the most frequently studied compounds in organic semiconducting materials. ${ }^{1-7}$ Advantages of those molecules in these field are thought to attribute to their unique structural features: all sulfur atoms are positioned at the molecular periphery, facilitating multiple short intermolecular $S \cdots S$ contacts and increasing the effective dimensionality of the electronic structure so that they may posses enhanced transport properties. ${ }^{8-1 l}$

Molecules composed of as many as five fused rings (pentathienoacene) have been reported so far. however. the synthetic routes to those compounds are deemed still inefficient. $^{\text {2.13 }}$ Recently an improved synthesis of pentathienoacene and extension of the series to make heptathienoacene ([7]TA shown in Fig. 1.) has been reported. ${ }^{\text {14.15 }}$ The oligothienoacenes indeed have shown more efficient molecular packing than oligothiophenes. As other notable structures. thiophene-based annulations of linear $\beta$-oligothiophenes give helical carbon-sulfur $\left(\mathrm{C}_{2} \mathrm{~S}\right)$ n oligomers for large $n$. possessing a curvature characteristic of helicenes $([\mathrm{n}] \mathrm{TH}$. shown in Fig. 2). These will be the focus of exploring the semiconducting properties of the materials in organic fieldeffect transistors. However. systematic studies of electronic properties of fused oligothiophenes and conjugated polymers and examples which establish the relationships between the structures and the electronic properties in these compounds are still lacking.

Here we have studied the geometrical and electronic structures of fused oligothiophene oligomers by calculating the HOMO-LUMO gaps. Moreover, geometric and electronic properties of their conjugated polymers were analyzed by extrapolating the HOMO-LUMO band gap data of their oligomeric series. These studies to establish the relationships between the structure and the electronic properties of conjugated polymer may lead to a better understanding the structural variables and eventually controlling the band gaps in fused oligothiophene oligomers and polymers.

\section{Computational Methods}

For an initial validation of computational method. the isomer of thienoacene [4]TA were fully optimized using Hartree-Fock (HF/6-31G*) and DFT methods (B3LYP/6$31 \mathrm{G}^{*}, \mathrm{~B} 3 \mathrm{LYP} / 6-31 \mathrm{G}^{* *}, \mathrm{~B} 3 \mathrm{LYP} / 6-31+\mathrm{G}^{*}$ ), and the result-

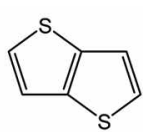

[2]TA

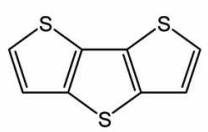

[3]TA

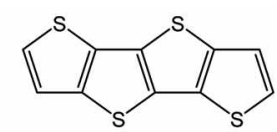

[4]TA

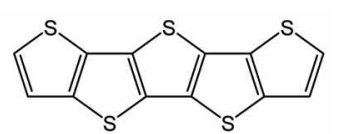

[5]TA

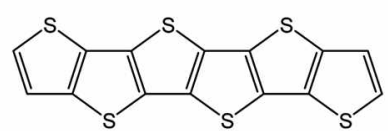

[6]TA<smiles>c1cc2sc3c(sc4c3sc3c5sc6ccsc6c5sc34)c2s1</smiles>

[7]TA

Figure 1. Chemical structure of [n] thienoacenes (TA).<smiles>c1cc2ccsc2s1</smiles>

[2] TH

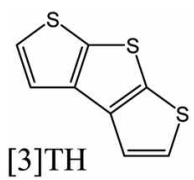

[4]TH

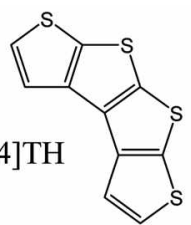

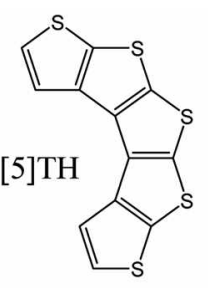

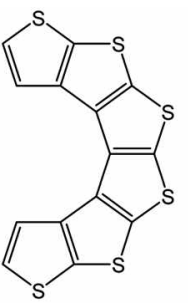

[6]TH<smiles>c1cc2c(s1)sc1sc3sc4sc5sccc5c4c3c12</smiles>

[7] TH

Figure 2. Chemical structure of [n] thienohelicenes ( $\mathrm{TH}$ ). 
Table 1. Geonetric data of [4]TA from crystal data and varions methods

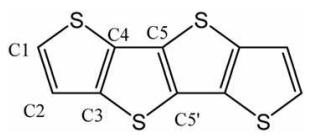

\begin{tabular}{lccccc}
\hline & $\mathrm{C} 1-\mathrm{C} 2$ & $\mathrm{C} 2-\mathrm{C} 3$ & $\mathrm{C} 3-\mathrm{C} 4$ & $\mathrm{C} 4-\mathrm{C} 5$ & $\mathrm{C} 5-\mathrm{C5}^{\prime}$ \\
\hline crystal data & 1.359 & 1.414 & 1.388 & 1.417 & 1.383 \\
$\mathrm{HF} / 6-31 \mathrm{G}^{*}$ & 1.344 & 1.433 & 1.363 & 1.429 & 1.363 \\
$\mathrm{~b} 31 \mathrm{yp} / 6-31 \mathrm{G}^{*}$ & 1.367 & 1.424 & 1.393 & 1.421 & 1.394 \\
$\mathrm{~b} 31 \mathrm{yp} / 6-31 \mathrm{G}^{* *}$ & 1.367 & 1.424 & 1.393 & 1.421 & 1.394 \\
$\mathrm{~b} 31 \mathrm{pp} / 6-31+\mathrm{G}^{*}$ & 1.370 & 1.425 & 1.395 & 1.422 & 1.395 \\
\hline
\end{tabular}

ing geometries were compared with crystal structure. The crystal and optinized parameters of [4]TA are shown in Table 1. According to the results, the B3LYP/6-3IG(d) method is found to give molecular structures reasonably matched with the experimental geonetries for tetrathienoacene.

By means of the Gaussian 98 program. geometries of 12 molecules for [n]thienoacenes $(n=2-7)$ and [n]thienolhelicenes $(n=2-7)$ have been fully optinized with the hybrid density functional theory (DFT) B3LYP method using the 6$3 \mathrm{IG}(\mathrm{d})$ basis set. ${ }^{10}$
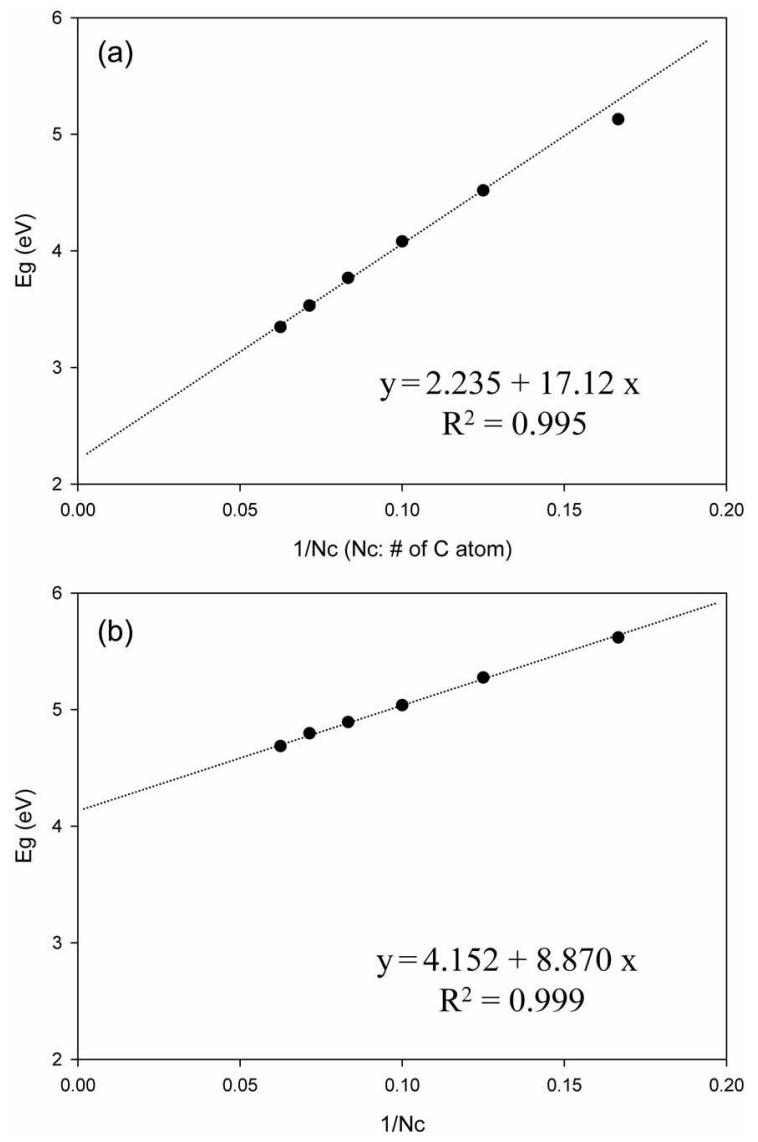

Figure 3. HOMO-LUMO gaps (Eg) of n-TA (a) and n-TH (b) oligomers as a function of $1 / \mathrm{Nc}$, where $\mathrm{Nc}$ is the number of carbon atoms along the chain.
Table 2. Linear regression data of oligomer band gaps as a function of $\mathrm{Nc}$, the number of carbon atoms along the chain using eq. (1)

\begin{tabular}{ccc}
\hline system & {$[\mathrm{n}] \mathrm{TA}$} & {$[\mathrm{n}] \mathrm{TH}$} \\
\hline $\mathrm{a}$ & 17.12 & 8.87 \\
$b=E g$ & 2.235 & 4.152 \\
$\mathrm{R}^{2}$ & 0.995 & 0.999 \\
\hline
\end{tabular}

Gap values from the B3LYP:6-3IG(d) methodology have been used, a and $\mathrm{b}$ in $\mathrm{eV}$.

\section{Results and Discussion}

Dependency of the HOMO-LUMO gaps ( $E g$ ) of oligomers. Molecular structures of all oligomers of $[\mathrm{n}] \mathrm{TA}$ and [n]TH (where $n=2-7$. as shown in Fig. 1-2) are optimized using B3LYP/6-3lG(d) method. Figure 3 indicates there is a close linear relationship between HOMO-LUMO gaps $(E g)$ and $1 / \mathrm{Nc}$ ( $\mathrm{Nc}$ : number of $\mathrm{C}$ atoms). The slopes are shown by 17.12 for $[\mathrm{n}] \mathrm{TA}$ and $8.87[\mathrm{n}] \mathrm{TH}$ from the linear relationship (shown in Fig. 3). Obviously the slopes indicate the conjugation length dependency of the HOMO-LUMO gaps $(E g)$. The value of thienoacenes (TA) series is similar to other known oligothiophenes series. However. it is noted that the slope of thienohelicene series is smaller than thienoacenes (TA) series. that is, the conjugation length dependency of the HOMO-LUMO gaps $(E g)$ in the thienohelicene (TH) system is smaller than other known thiophene system.

Extrapolation of the gaj. The bandgap $(E g)$ in an extended system is defuned as the difference between the lowest band energy in the conduction band and the highest band energy in the valence band. In studying the dependency of the HOMO-LUMO gaps of oligomers. we observed a trend for larger oligomers: ${ }^{17}$

$$
E g\left(\mathrm{Nc}_{\mathrm{c}}\right)=a \mathrm{Nc}+b . \quad \text { where } b=E g
$$

For all polymers studied. Nc was chosen as the number of the carbon atoms along the conjugated chain. This allowed a comparable scale for the : $a$ ' values in the extrapolations for different conjugated systems. ' $a$ ' and ' $b$ ' were determined by linear regression. ' $b$ ' is identified as $E g$. Selected statistical data were collected in Table 2 . The correlation was satisfactory so that it is reasonable to assume that the linear trend in $1 / \mathrm{Nc}$ would continue as $\mathrm{Nc}$ increases to infinity. Note that the ' $\alpha$ ' values are large differences between [n]thienoacenes and [n]thienohelicenes systems shown in Table 2 and Figure 3.

As shown in Table 2 and Figure 3. the band gap of polythienoacene is predicted to be $2.23 \mathrm{eV}$ from HOMOLUMO gaps of oligothienoacenes by extrapolating to the infunite chain. It is noticed that this is close to the value obtained from an extrapolation of Imax of oligothienoacenes (see ref. 15). ${ }^{15}$ As an alternative way for predicting bandgaps, the HOMO-LUMO calculation of molecular oligomers should be a reliable and efficient method for predicting bandgaps of polythienoacenes. ${ }^{17}$ Using the same way. the bandgap of poly thienohelicene also is predicted by $4.15 \mathrm{eV}$ from the oligothienohelicene. However. the dependency of the oligo-helicene series turns out smaller than oligo-acene 
series (17.12 for [n] TA and 8.87 [n] TH as shown in Table 2). It may due to helical structure of oligo-helicene and might affect the band gap. which is not clearly rationalized yet.

In sumnary, the geometrical and electronic structures of the oligothiophenes have been investigated using a density functional theory (DFT) B3LYP method. HOMO-LUMO gaps of fused oligothiophenes $(n=2-7)$ were calculated and data were compared with those of related compounds such as thienoacene and thienohelicene series to analyze their structural features. The conjugation length dependency of the HOMO-LUMO gaps $(E g)$ in thienoacene series showed similar profiles with the oligothiophenes. The dependency of thienohelicene series turned out smaller than the thenoacene homologs. The band gaps of their polymers were predicted using extrapolation of HOMO-LUMO energy gaps of oligomers, which would be an alternative way for predicting bandgaps as a reliable and a practical method. The above prediction of bandgaps for fused polythiophenes will facilitate a deep understanding and inproving their properties with desirable characteristics as well as a further synthetic approach to the fused thieophene derivatives

Acknowledgement. The author C.S. Ra thanks to the support from Yeungnam University. We thank Dr. K.T. Park of Physics Department at Kookmin University for helpful discussion.

\section{References}

1. Katz, H. E.; Bao, Z. Gilat, S. L. Acc. Chem. Res. 2001. 3f, $359-$ 369

2. Fichou. D. J. Mater Chem. 2000, 10,571-588.

3. Roncali. J. Acc. Chem. Res. 2000. 33. 147-156.

4. Izumi, T.: Kobashi, S.: Takimiva, K.: Aso. Y: Otsubo. T. J. Am. Chem. Soc. 2003. 125. 5286-5287.

5. Krömer, J: Rios-Carreras, I: Fuhrmann. G: Musch. C.: Wunderlin. M.: Debaerdemaeker. T.: Mena-Osteritz. E.: Bäuerle. P. Angew: Chem., Int. Ed. 2000.39.3481-3486.
6. Casado. J.: Pappentus. T. M.: Miller. L. L.: Mann. K. R.: Orti. E.: Viruela. P. M.: Pou-Amerigo. R.: Hernandez. V: Navarette. J. T. L. J.Am. Chem. Soc. 2003. 125. 2524-2534

7. Huynh. W. U.: Dittmer. J. J.: Alivastatos. A. P. Science 2002, 295. $2425-2+27$

8. Nielsen, M. B.: Schreiber, M.: Baek, Y. G.: Seiler. P: Lecomte, S.; Boudon. C.: Tykwinski. R. R.: Gisselbrecht. T.-P.: Gramlich. V: Skin11er. P. T.: Bosshard. C.: Gunther. P.: Gross. M.: Diederich. F. Chent-Eur, J. 2001. 7.3263-3280.

9. (a) Zhao, Y; Tykwinski, R. R. J. Am. Chem. Soc. 1999, 121, 458459. (b) Zhao, Y.; McDonald. R.; Tykwinski. R. R. J. Org. Chem. 2002. 67, 2805-2812.

10. Gaab. K. M.: Thompson. A. L.: Xuı. J.: Martinez. T. T.: Bardeen. C. J. J. Ant Chent Soc. 2003. 125.9288-9289.

11. (a) Londergan. T. M.: You. Y: Thompson. M. E.: Weber. W. P. Iacromolecules 1998. 31, 2784-2788. (b) Wilson. J. N. Windscheif. P. M.: Evans, U.: Myrick. M. L.: Bunz, U. H. F. Bacronolecules 2002. 35.8681-8683

12. Mazaki. Y: Kobayashi. K. Tetrahedon Lett. 1989. 30. 33153318.

13. Sato. N.: Mazaki. Y: Kobayashi. K.: Kobayashi. T. J. Chent. Soc. Perkin Trans. $21992.765-770$.

14. (a) Rajca. A.; Miyasaka, M.: Pink, M.: Wang, H.: Rajca, S. J. Am. Chem. Soc. 2004, 126. 1521 1. (b) Mivasaka. M.; Rajca, A. J. Org. Chent 2006. 7l. 3264.

15. Zhang. X.: Côté. A. P.: Matzger. A. T. J. Ant Chem. Soc. 2005. 127. 10502 .

16. Frisch. M. J.: Trucks. G. W: Schlegel. H. B.: Scuseria, G. E: Robb. M. A.; Cheeseman, J. R.: Zakrzewski, V. G.; Montgomery. J. J. A.; Stratmann, R. E.; Burant. J. C.: Dapprich, S.: Millam, J M.: Daniels. A. D.: Kuditi. K. N.: Strain. M. C.: Farkas. O.: Tomasi. I.: Barone. V: Cossi. M.: Cammi. R: Mennucei. B: Ponelli. C.: Adamo. C.: Clifford. S.: Ochterski. J.: Petersson. G. A.; Avala, P. Y.: Cui, Q: Morokuma. K.: Rega, N.: Salvador. P: Dannenberg, J. J.: Malick. D. K; Rabuck, A. D; Raghavachari. K: Foresman. J. B. Cioslowski. J.; Ortiz. J. V.: Baboul. A. G: Stefanov. B. B.: Liu. G.: Liasherlko. A.: Piskorz. P.: Komaromi. I.: Gomperts. R.: Martin. R. L.: Fos. D. J.: Keith. T.: Al-Laham. M. A.: Peng. C. Y.: Nanayakkara. A.: Challacombe. M.: Gill. P. M. W.: Johnson, B.: Chen. W: Wong, M. W: Andres. J. L.; Gonzalez. C.: Head-Gordon, M.: Replogle. E. S.: Pople. J. A. Gaussian 98. Revision A.1 1.3: Gaussian. Inc.: Pittsburgh, PA. 2002.

17. Yang. S.: Olisherski. P.: Kertesz. M. Symthetic Metals 2004. $1+1(1-2) \cdot 171$ 